\title{
Contrasting effects of climate on grey heron, malleefowl and barn owl populations
}

\author{
Maria Boyle ${ }^{\mathrm{A}}$ and Jim Hone $\mathrm{A}, \mathrm{B}$ \\ Anstitute for Applied Ecology, University of Canberra, Canberra, ACT 2601, Australia. \\ ${ }^{B}$ Corresponding author. Email: Jim.Hone@canberra.edu.au
}

\begin{abstract}
Context. The population dynamics of many wildlife species are associated with fluctuations in climate. Food and abundance may also influence wildlife dynamics.

Aims. The present paper aims to evaluate the relative effects of climate on the annual instantaneous population growth rate $(r)$ of the following three bird species: grey heron and barn owl in parts of Britain and malleefowl in a part of Australia.

Methods. A priori hypotheses of mechanistic effects of climate are derived and evaluated using information theoretic and regression analyses and published data for the three bird species. Climate was measured as the winter North Atlantic Oscillation (NAO) for herons and owls, and rainfall and also the Southern Oscillation Index (SOI) for malleefowl.

Key results. Population dynamics of grey heron were positively related to the winter NAO, and of malleefowl were positively related to annual rainfall and related in a non-linear manner to SOI. By contrast, population dynamics of barn owl were very weakly related to climate. The best models for the grey heron differed between time periods but always included an effect of the NAO.

Conclusions. The annual population growth rate of grey heron, malleefowl and barn owl show contrasting relationships with climate, from stronger (heron and malleefowl) to weaker (barn owl). The results were broadly consistent with reported patterns but differed in some details. Interpretation of the effects of climate on the basis of analyses rather than visual assessment is encouraged.
\end{abstract}

Implications. Effects of climate differ among species, so effects of future climate change may also differ.

Additional keywords: barn owl, grey heron, malleefowl, numerical response, wildlife population dynamics.

Received 17 December 2010, accepted 6 October 2011, published online 21 December 2011

\section{Introduction}

Climate may directly and indirectly influence wildlife population dynamics (Andrewartha and Birch 1954; Caughley et al. 1987; Newton 1998). Climate may influence food availability and hence survival and fecundity rates of wildlife. Survival may be influenced because of effects on thermoregulation. Alternatively, climate may influence the ability of a population to convert food into population growth, separate from an effect on food availability. This latter possibility, the ability to convert food into population growth, is the focus of the present study.

A considerable amount of annual variation in the size of bird populations (Sæther et al. 2003) and annual growth rate of mammal populations (Hone and Clutton-Brock 2007) has been reported as related to large-scale climate phenomena in the northern hemisphere, such as the winter North Atlantic Oscillation (NAO) (Hurrell et al. 2003; Stenseth et al. 2003). In the southern hemisphere, the Southern Oscillation Index (SOI) is an analogous largescale climate index (Stenseth et al. 2003) and may also be related to wildlife dynamics.
There are many examples in the literature of bird population dynamics being related to climate (Newton 1998; Knape and de Valpine 2011). Such associations have been described on the basis of visual assessment of apparent patterns or formal analysis, with the latter being encouraged. Three bird species were examined in the present study to re-evaluate, using analysis, some reported associations of dynamics and climate.

The British Trust for Ornithology's Census of Heronries for the grey heron (Ardea cinerea) has occurred annually in England and Wales since 1928. The data on heron abundance used herein have been described several times in the ecological literature (e.g. Stafford 1971; Putman and Wratten 1984; Caughley and Sinclair 1994; Begon et al. 2006), with the grey heron population reported to experience significant weather related population crashes because of severe winters and temperatures below freezing. The reports typically contain no formal analysis. These crashes are followed by relatively fast recovery periods (Stafford 1971; North and Morgan 1979). The fast recovery of the population indicates a return towards a dynamic equilibrium, suggesting that in addition to weather- 
related variables, density-dependent (regulatory) processes in grey heron populations are influential (Lack 1954; Begon et al. 2006).

Malleefowl (Leipoa ocellata) occurs across parts of southern Australia. The dynamics of this species have been linked to climate measured as rainfall (Priddel and Wheeler 2003). This may be associated with food availability or possibly the unique nesting behaviour involving laying eggs in an earth and leaf litter mound, the latter which when wet from rain provides the heat for incubation of the eggs (Frith 1962; Priddel and Wheeler 2003).

By contrast, the winter survival of the barn owl (Tyto alba) in southern Scotland has not been historically associated with climate (Taylor 1994; Newton 1998). Taylor (1994) did not present any formal quantitative analyses of the relationship between the annual population growth rate of barn owls and climate, such as the winter NAO. Models of a numerical response describing the positive relationship between the annual growth rate of the owl population and the owl's main prey, field voles (Microtus agrestis) have been developed (Hone and Sibly 2002).

The aim of the present paper is to evaluate alternative hypotheses, expressed as models, relating annual wildlife population growth rate $(r)$ to climate for three bird species, namely grey heron, malleefowl and barn owl. The analyses are new for each species and are derived from alternative a priori mechanistic hypotheses.

\section{Models}

Models were developed in accordance with the method of multiple working hypotheses, involving the development of several hypotheses before undertaking research in an attempt to explain the underlying phenomenon of interest (Chamberlin 1965; Anderson 2008). The mechanistic models (Sibly and Hone 2002) are based on assumptions about the effect of food on wildlife dynamics and assumed effects of climate on the effect of food. Hence, the models have a deterministic skeleton and a stochastic climate forcing, in the sense of Coulson et al. (2004). A priori hypotheses of effects on specific populations were supported as were simple models with few covariates (Knape and de Valpine 2011). The models are nondemographic and non-spatial, after Hone and Clutton-Brock (2007) and Hone et al. (2011), and no models have only density terms because the present study is not a study of density dependence per se.

It has been hypothesised, and empirical data support the hypothesis, that climate may influence annual $r$ of wildlife (Caughley et al. 1987; Hone and Clutton-Brock 2007). The positive relationship (Eqn 1) between population growth rate $(r)$ and food availability (V) (May 1981) may be modified (Eqn 2) by climate (Hone and Clutton-Brock 2007). Climate may directly influence the slope (parameter $\beta$ in Eqn 1) of the $r$-food relationship in a linear manner. That is, climate influences the capacity of a wildlife population to convert food into population growth. This is separate from an effect of climate on food availability, which is not evaluated here because of the lack of food data for many species.
Model 1 is derived from the linear $r$-food relationship (the numerical response) of

$$
r=\alpha+\beta \mathrm{V} .
$$

If the slope is related to climate $(W)$ as

$$
\beta=\gamma+\delta \mathrm{NAO},
$$

then substituting Eqn 2 into Eqn 1 and rearranging gives

$$
r=a+b \mathrm{NAO},
$$

where $a=\alpha+\gamma \mathrm{V}$ and $b=\delta \mathrm{V}$. This is Model 1 (Table 1, Fig. 1a). It is hypothesised, on the basis of the literature (Stafford 1971), that very cold winters in Britain (represented by negative values of the winter NAO) would have negative effects on grey heron $r$ because water freezing would limit the capacity of herons to feed on aquatic organisms, and the lessening of climate stress (represented by positive values in the winter NAO) would result in an increase in abundance and $r$. Barn owl may not experience such climate effects because their main food, vole (Taylor 1994), does not live in ponds and streams.

Climate can have complex, non-linear, additive and interactive effects on population dynamics (Hone and CluttonBrock 2007; Hone et al. 2011). Equation 2 can be modified to include a quadratic term to reflect a non-linear effect of climate (Table 1), which after rearranging gives Model 2 (Table 1, Fig. 1b). A quadratic relationship between annual $r$ and rainfall has been reported for kangaroos (Caughley et al. 1984) and malleefowl (Priddel and Wheeler 2003) in parts of eastern Australia.

Model 3 is derived (Table 1, Fig. 1c) from the additive model of Hone and Sibly (2002) by assuming that climate influences the parameter $\beta$, again reflecting the influence on the capacity of the food to be converted to population growth. That can be shown to lead to Model 3, with additive effects of climate $(W)$ and abundance $(H)$ (Table 1$)$. Model 4 is derived from the ratio model (Table 1) of population dynamics (May 1974) by assuming that the parameter $\mathrm{J}$ in the ratio model is related to climate (Hone and Clutton-Brock 2007), and that predicts an interactive effect of the climate and abundance $(W \times H)$ and an additive effect of abundance $(H)$ (Table 1, Fig. 1d).

Models 2 and 4 have a maximum annual $r$. A maximum was considered an essential feature of a numerical response relationship (Berryman et al. 1995). In Model 2, the maximum occurs when the curve is concave down. The intercept $a$ in Model

Table 1. Numerical response relationships of annual instantaneous population growth rate $(r)$ with food $(V)$ and abundance $(H)$, and the derived model equations of annual $r$ and climate $\left(W_{t-1}\right)$ and abundance for grey heron, malleefowl and barn owl populations

The parameter in each model hypothesised to be influenced by climate in a linear or curved manner is also shown

\begin{tabular}{lcccc}
\hline $\begin{array}{l}\text { Numerical } \\
\text { response }\end{array}$ & $\begin{array}{l}\text { Parameter } \\
\text { influenced }\end{array}$ & $\begin{array}{l}\text { Linear or } \\
\text { curved }\end{array}$ & Model equation & $\begin{array}{c}\text { Model } \\
\text { number }\end{array}$ \\
\hline$r=\alpha+\beta \mathrm{V}$ & $\beta$ & Linear & $r=a+b W_{\mathrm{t}-1}$ & 1 \\
$r=\alpha+\beta \mathrm{V}$ & $\beta$ & Curved & $r=a+b W_{\mathrm{t}-1}+c W_{\mathrm{t}-1}^{2}$ & 2 \\
$r=\alpha+\beta \mathrm{V}+\gamma \mathrm{H}$ & $\beta$ & Linear & $r=a+b W_{\mathrm{t}-1}+d H_{\mathrm{t}}$ & 3 \\
$r=r_{\mathrm{m}}(1-\mathrm{JH} / \mathrm{V})$ & $\mathrm{J}$ & Linear & $r=a+f W_{\mathrm{t}-1} \times H_{\mathrm{t}}+d H_{\mathrm{t}}$ & 4 \\
\hline
\end{tabular}


4 is the maximum, namely the annual intrinsic growth rate $\left(r_{\mathrm{m}}\right)$ if parameters $d$ and $f$ are negative and $W$ is positive.

In summary, the four models are derived mechanistically from an assumption of an effect of climate on the capacity of wildlife to convert food into population growth.

\section{Materials and methods}

Climate was measured for the northern hemisphere birds (grey heron and barn owl) by the winter NAO, which is generated by
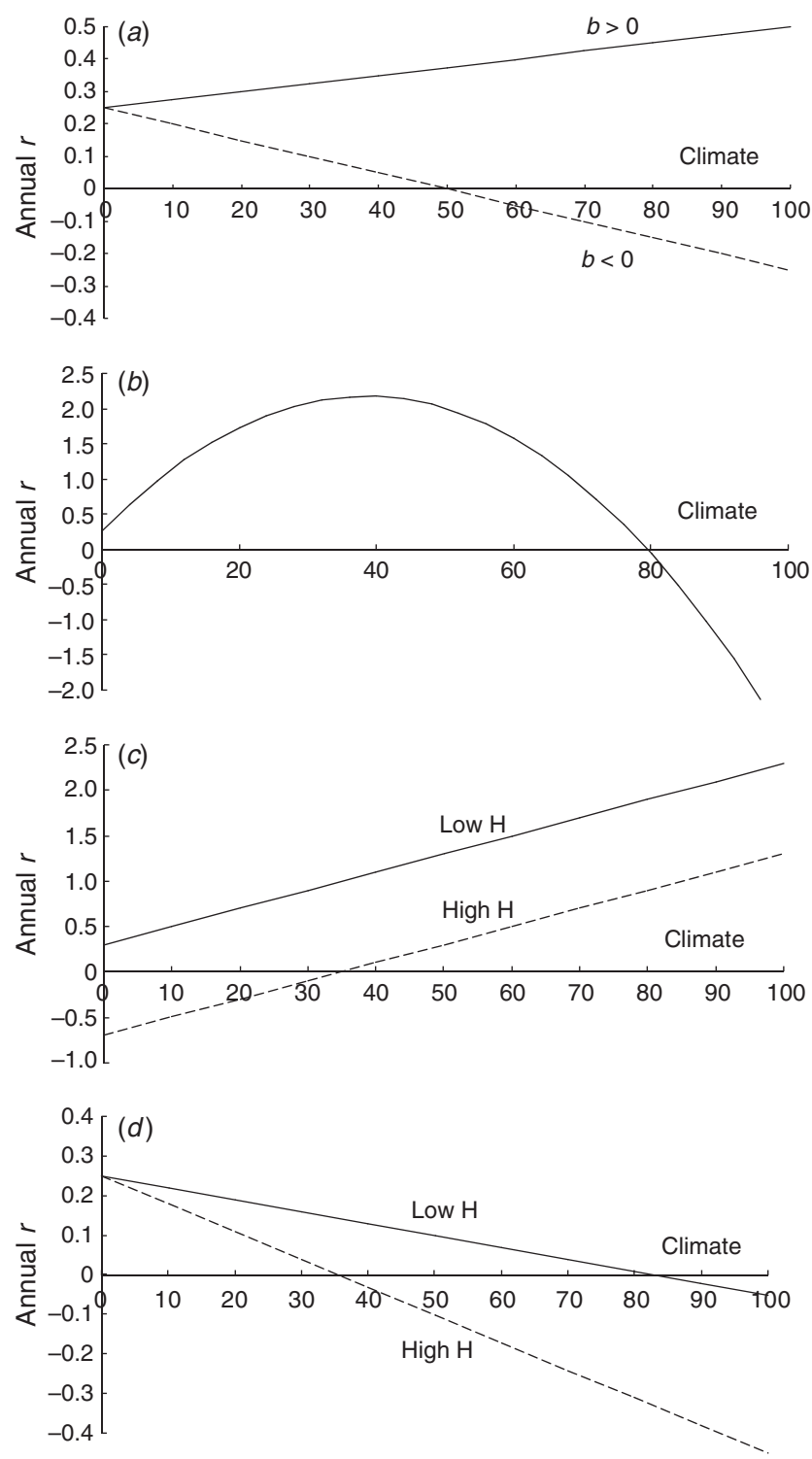

Fig. 1. Models of the derived relationships between annual instantaneous population growth rate $(r)$ of wildlife and climate. $(a)$ Positive $(b>0)$ and negative $(b<0)$ linear relationships in Model 1, $(b)$ quadratic relationship in Model 2, $(c)$ positive $(b>0)$ linear relationships in Model 3, with low (solid line) and high (dashed line) abundance $(\mathrm{H})$, and $(d)$ linear negative interaction of climate and low (solid line) and high (dashed line) abundance $(H)$ in Model 4. Model equations are shown in Table 1. Numerical values are hypothetical. air-pressure differentials extending from Iceland to Portugal and is considered to be the dominant climate pattern in the North Atlantic region (Hurrell 1995; Hurrell et al. 2003). The NAO experiences the most extreme fluctuations during the winter months from November to April (Stenseth et al. 2003). A positive NAO value corresponds broadly to wet and windy weather in Britain and a negative NAO to colder, drier weather (Hurrell 1995; Hurrell et al. 2003). The winter NAO index values across relevant time periods are available from the Jim Hurrell website (http://www.cgd.ucar.edu/cas/jhurrell, verified 28 November 2011). Climate data for the malleefowl study were annual rainfall from Priddel and Wheeler (2003: table 1) and SOI from the Bureau of Meteorology website (www.bom.gov.au, verified 28 November 2011). For the years of study, the annual rainfall and mean SOI for the year were not correlated $\left(r^{2}=0.05\right.$, d.f. $\left.=9, P>0.05\right)$. Extreme negative SOI values usually correspond to droughts in eastern Australia.

The abundance data for grey herons were from the British Trust for Ornithology's census of heronries from 1928 to 1969 for England and Wales, measured by the number of nests occupied as an approximation to the number of breeding pairs of adults (Stafford 1971). A highly variable pattern is evident in the grey heron abundance data from 1928 to 1969 (Fig. 2). This may have been in part due to the influence of two factors. Shooting of herons (a form of predation) was legal in Britain up until 1954 (North and Morgan 1979) and organochlorines were reported (Stafford 1971) as in wide use in the 1960s. Data were analysed for two separate time periods, i.e. 1928-1954 and 1955-1969, to separate these effects. A preliminary analysis of the two time periods indicated that the mean winter NAO for 1928-1954 was higher $(-0.08)$ than that for 1955-1969 (-1.42). The higher coefficient of variation in the winter NAO during the first time period (19.79) indicated much greater variability than in the later period $(-1.33)$.

Malleefowl abundance (Fig. 3) was monitored intensively in a patch of remnant mallee vegetation in western New South Wales (Priddel and Wheeler 2003). Data on population size were from their table 6. A significant quadratic regression was reported between annual population growth rate $(r)$ and annual rainfall (Priddel and Wheeler 2003: fig. 6). That published regression is Model 2 (Table 1) in the present study.

Barn owl abundance data (Fig. 4) are from Taylor's (1994) excellent study of the barn owl and are based on census data. The abundance of pairs of barn owls was estimated via the minimum number known to be alive in the breeding season (spring and

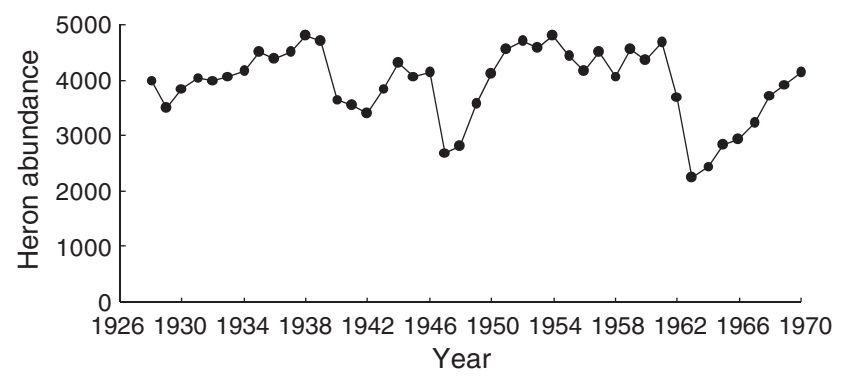

Fig. 2. Abundance of grey herons in England and Wales from 1928 to 1969. Data are from the study of Stafford (1971). 
summer) each year during close observation and mark-recapture of owls (Taylor 1994; Hone and Sibly 2002).

The annual instantaneous population growth rate $(r)$ was estimated as $r=\ln \left(H_{\mathrm{t}+1} / H_{\mathrm{t}}\right)$, from the abundance $(H)$ of each species (Caughley and Sinclair 1994). The regressions were calculated using linear and non-linear least-squares regressions, using computer software SAS version 9.1. Model selection was based on identifying the model with the lowest

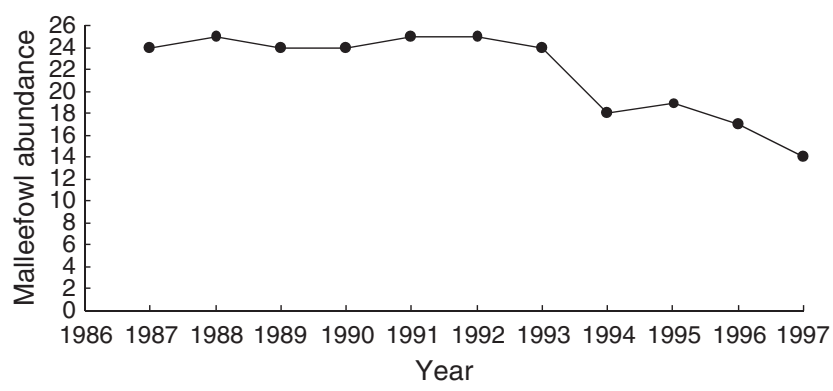

Fig. 3. Abundance of malleefowl in a part of western New South Wales. The summer of 1987-88 is shown as 1987 and so on. Data are from the study of Priddel and Wheeler (2003).

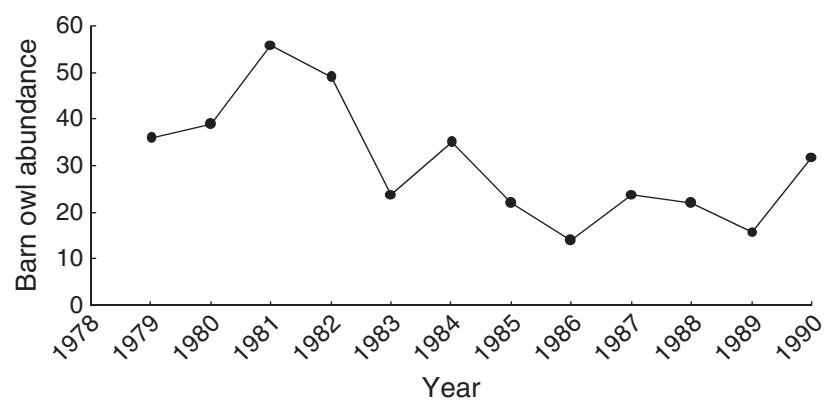

Fig. 4. Abundance of barn owls in southern Scotland from 1979 to 1990. Data are from the study of Taylor (1994).
Akaike information criterion corrected for small samples (AICc), in conjunction with the highest Akaike weight $\left(\omega_{\mathrm{i}}\right)$ (Burnham and Anderson 2001; Johnson and Omland 2004; Anderson 2008). The coefficient of determination $\left(R^{2}\right)$ was also estimated to assess goodness-of-fit one model at a time, as suggested by Burnham and Anderson (2001).

\section{Results}

\section{Grey heron 1928-1954}

The analysis of annual $r$ against climate (winter NAO) and abundance $(H)$ showed that the model with the highest Akaike weight $\left(\omega_{1}=0.440\right)$ was Model 1 (Table 2$)$. The fitted regression for the model was

$$
r=0.008+0.053 \mathrm{NAO},
$$

with a positive effect of NAO (Fig. 5, Table 3 ). The regression was highly significant $\left(F_{1,25}=20.53, P<0.0001, R^{2}=0.451\right)$. Details of parameter estimates for all models are shown in Table 3.

Table 2. Number of parameters $(K)$, residual sum of squares (RSS), AICc, $\Delta$ AICc, Akaike weights $\left(\omega_{i}\right)$ and the coefficient of determination $\left(R^{2}\right)$ for models of grey heron population dynamics in parts of Britain and climate (NAO) for two time periods

For each time period, the model with the highest Akaike weight is shown in bold

\begin{tabular}{lcccccc}
\hline Model & $K$ & RSS & AICc & $\Delta$ AICc & $\omega_{\mathrm{i}}$ & $R^{2}$ \\
\hline $1928-1954$ & & & & & & \\
$\mathbf{1}$ & $\mathbf{3}$ & $\mathbf{0 . 2 2 6}$ & $\mathbf{- 1 2 2 . 1}$ & $\mathbf{0 . 0 0 0}$ & $\mathbf{0 . 4 4 0}$ & $\mathbf{0 . 4 5 1}$ \\
2 & 4 & 0.224 & -119.6 & 2.511 & 0.125 & 0.456 \\
3 & 4 & 0.211 & -121.1 & 0.931 & 0.275 & 0.487 \\
4 & 4 & 0.219 & -120.1 & 2.010 & 0.161 & 0.466 \\
$1955-1969$ & & & & & & \\
1 & 3 & 0.350 & -48.20 & 1.018 & 0.240 & 0.135 \\
2 & 4 & 0.349 & -44.40 & 4.810 & 0.036 & 0.136 \\
3 & 4 & 0.260 & $\mathbf{- 4 8 . 8 1}$ & 0.406 & 0.326 & 0.356 \\
$\mathbf{4}$ & $\mathbf{4}$ & $\mathbf{0 . 2 5 3}$ & $\mathbf{- 4 9 . 2 2}$ & $\mathbf{0 . 0 0 0}$ & $\mathbf{0 . 3 9 9}$ & $\mathbf{0 . 3 7 4}$ \\
\hline
\end{tabular}

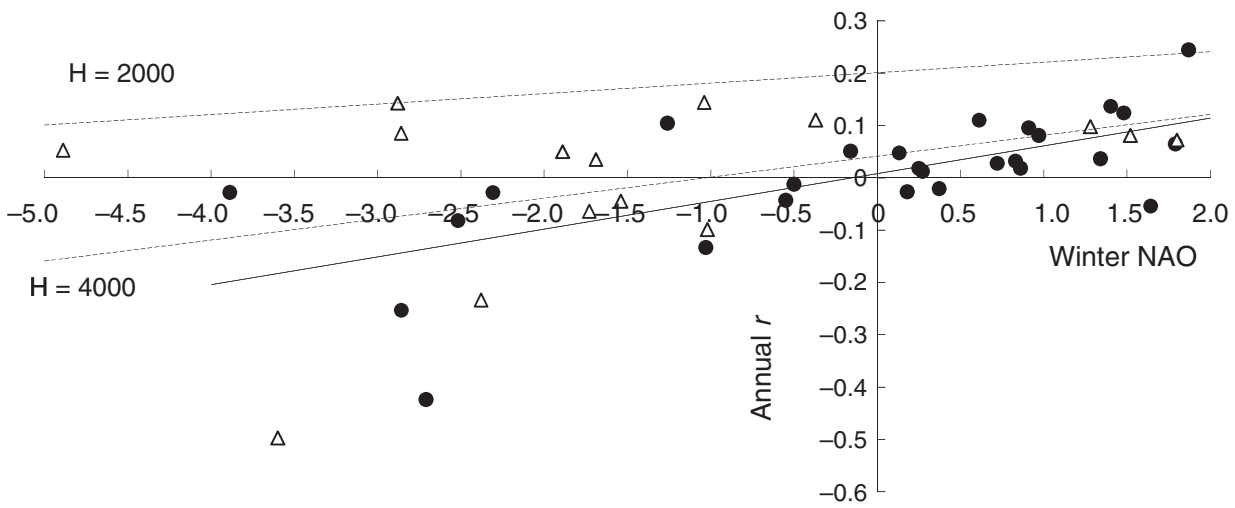

Fig. 5. Relationships between annual grey heron $r$ in parts of Britain and winter North Atlantic Oscillation (NAO), for 1928-1954 (solid circles and solid line) and 1955-1969 (open triangles and dashed lines). The lines are the best-fitting regressions for each time period. For the time period 1955-1969, the best-fitting model is shown for two population sizes $(H=2000$ and $H=4000)$ to demonstrate the interactive nature of the best-fitting model. 


\section{Grey heron 1955-1969}

The analysis of annual $r$ and the NAO and $H$ showed that the model with the highest Akaike weight $\left(\omega_{4}=0.399\right)$ was Model 4 (Table 2). The fitted regression for the model was

$$
r=0.361+0.00001 \mathrm{NAO} \times H-0.00008 H,
$$

with a positive effect of the interaction between $\mathrm{NAO}$ and $H$ and a negative effect of $H$ (Fig. 5, Table 3). The regression was marginally non-significant $\left(F_{2,12}=3.58, P=0.060\right)$. The model with the second-highest support (Model 3) had an Akaike weight of 0.326 , which is only slightly lower than that of Model 4 (Table 2), indicating similar relative support. There was an unusual observation in 1968-69 when the winter NAO was -4.89 but the heron population grew slightly $(r>0)$. The intercept (0.361) was an estimate of the annual intrinsic growth rate $\left(r_{\mathrm{m}}\right)$.

\section{Malleefowl}

The best-fitting model $\left(\omega_{1}=0.383\right)$ of dynamics and annual rainfall $(\mathrm{mm})$ was Model 1 , the linear regression of annual $r$ and rainfall (Table 4). The fitted equation was

$$
r=-0.3854+0.00064 W
$$

with a positive effect of rainfall (Table 4, Fig. $6 a$ ). The regression was significant $\left(F_{1,9}=5.53, P=0.04, R^{2}=0.38\right)$. The relative support for other models was low (Table 4) and all parameter estimates are shown in Table 5. The second-best fitting model was the quadratic regression of annual $r$ and SOI (Table 4). The fitted equation (Table 4, Fig. 6b) was

$$
r=0.070-0.0021 \mathrm{SOI}-0.0019 \mathrm{SOI}^{2}
$$

Table 3. Parameter estimates $(E)$ and standard errors (s.e.) for models of grey heron population dynamics in parts of Britain for two time periods For each time period, the model with the highest Akaike weight is shown in bold. n.a. $=$ not applicable

\begin{tabular}{ccccccc}
\hline Model & \multicolumn{6}{c}{ Model parameter } \\
& & $a$ & $b$ & $c$ & $d$ & $f$ \\
\hline $1928-1954$ & & & & & & \\
$\mathbf{1}$ & E & $\mathbf{0 . 0 0 8}$ & $\mathbf{0 . 0 5 3}$ & n.a. & n.a. & n.a. \\
& s.e. & $\mathbf{0 . 0 1 8}$ & $\mathbf{0 . 0 1 2}$ & - & - & - \\
2 & E & -0.0003 & 0.059 & 0.004 & n.a. & n.a. \\
& s.e. & 0.026 & 0.017 & 0.008 & - & - \\
3 & E & 0.197 & 0.047 & n.a. & -0.00005 & n.a. \\
& s.e. & 0.146 & 0.013 & - & 0.00004 & - \\
4 & E & 0.238 & n.a. & n.a. & 0.00001 & -0.00006 \\
& s.e. & 0.146 & - & - & 0.000003 & 0.00004 \\
$1955-1969$ & & & & & & \\
1 & E & 0.042 & 0.033 & n.a. & n.a. & n.a. \\
& s.e. & 0.054 & 0.023 & - & - & - \\
2 & E & -0.040 & 0.037 & 0.001 & n.a. & n.a. \\
& s.e. & 0.0596 & 0.036 & 0.011 & - & - \\
3 & E & 0.437 & 0.042 & n.a. & -0.0001 & n.a. \\
4 & s.e. & 0.021 & 0.021 & - & 0.00005 & - \\
& E & $\mathbf{0 . 3 6 1}$ & n.a. & n.a. & $-\mathbf{0 . 0 0 0 0 8}$ & $\mathbf{0 . 0 0 0 0 1}$ \\
& s.e. & $\mathbf{0 . 1 8 7}$ & - & - & $\mathbf{0 . 0 0 0 0 5}$ & $\mathbf{0 . 0 0 0 0 0 5}$ \\
\hline
\end{tabular}

The regression was significant $\left(F_{2,8}=5.54, \quad P=0.03\right.$, $\left.R^{2}=0.58\right)$. The relative support for other models was low (Table 4) and all parameter estimates are shown in Table 5. The estimate of the maximum annual population growth rate was 0.07 .

\section{Barn owl}

The analysis of $r$ showed that the model with the highest Akaike weight $\left(\omega_{1}=0.495\right)$ was Model 1 (Tables 6, 7). The fitted regression for the model was

$$
r=-0.006-0.006 \mathrm{~W}
$$

which was highly non-significant $\left(F_{1,10}=0.01, P=0.94\right.$, $\left.R^{2}=0.001\right)$.

Table 4. Number of parameters $(K)$, residual sum of squares (RSS), AICc, $\triangle$ AICc, Akaike weights $\left(\omega_{\mathrm{i}}\right)$ and the coefficient of determination $\left(R^{2}\right)$ for models of malleefowl population dynamics in western New South Wales and climate measured as annual rainfall $(\mathrm{mm})$ and as mean annual Southern Oscillation Index (SOI)

The model with the highest Akaike weight is shown in bold

\begin{tabular}{ccccccc}
\hline Model & $K$ & RSS & AICc & $\Delta$ AICc & $\omega_{i}$ & $R^{2}$ \\
\hline Rainfall & & & & & & \\
$\mathbf{1}$ & $\mathbf{3}$ & $\mathbf{0 . 1 0 0 8}$ & $\mathbf{- 4 2 . 1 8 9 6}$ & $\mathbf{0}$ & $\mathbf{0 . 3 8 2 7}$ & $\mathbf{0 . 3 8 0}$ \\
2 & 4 & 0.0841 & -38.9428 & 3.2468 & 0.0755 & 0.483 \\
3 & 4 & 0.0813 & -39.3212 & 2.8684 & 0.0912 & 0.501 \\
4 & 4 & 0.0867 & -38.6059 & 3.5837 & 0.0638 & 0.467 \\
SOI & & & & & & \\
1 & 3 & 0.1235 & -39.9586 & 2.2310 & 0.1255 & 0.241 \\
2 & 4 & 0.0682 & -41.2425 & 0.9471 & 0.2383 & 0.581 \\
3 & 4 & 0.1204 & -35.0011 & 7.1885 & 0.0105 & 0.260 \\
4 & 4 & 0.1166 & -35.3535 & 6.8361 & 0.0126 & 0.284 \\
\hline
\end{tabular}
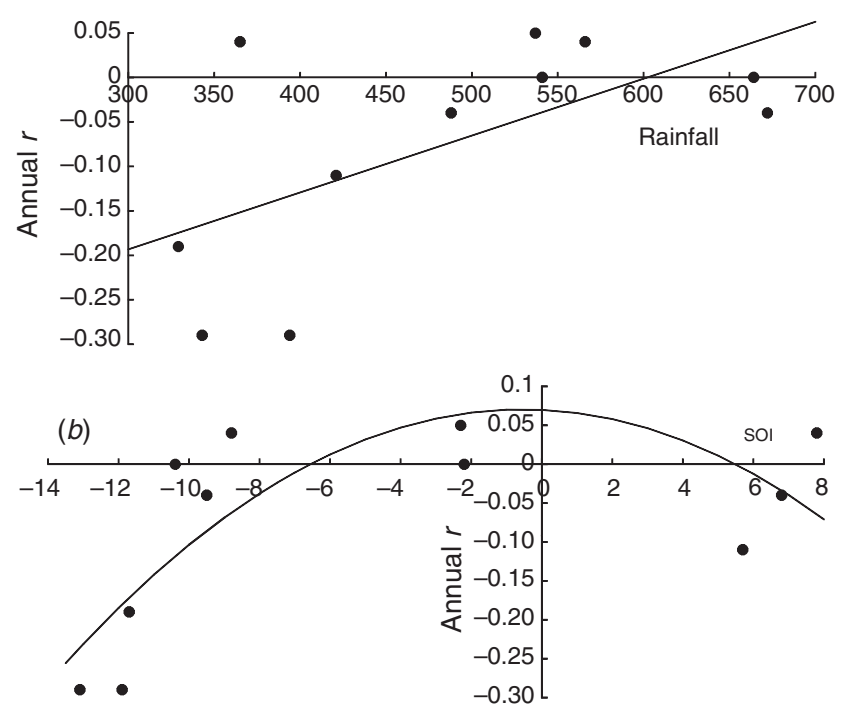

Fig. 6. Observed data and best-fitting regressions between annual population growth rate $r$ of malleefowl in western New South Wales and (a) annual rainfall ( $\mathrm{mm}$ ) using Model 1 and $(b)$ Southern Oscillation Index (SOI) using Model 2. Malleefowl data are from Priddel and Wheeler (2003). 
Table 5. Parameter estimates (E) and standard errors (s.e.) for models of malleefowl population dynamics in western New South Wales and climate measured as annual rainfall $(\mathrm{mm})$ and as mean annual Southern Oscillation Index (SOI)

The model with the highest Akaike weight is shown in bold

\begin{tabular}{ccccccc}
\hline Model & \multicolumn{7}{c}{ Model parameter } \\
& & $a$ & $b$ & $c$ & $d$ & $f$ \\
\hline Rainfall & & & & & & \\
$\mathbf{1}$ & $\mathbf{E}$ & $-\mathbf{0 . 3 8 5}$ & $\mathbf{0 . 0 0 0 6 4}$ & n.a. & n.a. & n.a. \\
& S.e. & $\mathbf{0 . 1 3 6}$ & $\mathbf{0 . 0 0 0 2 7}$ & - & - & - \\
2 & E & -1.184 & 0.0040 & -0.0000034 & n.a. & n.a. \\
& s.e. & 0.647 & 0.0027 & 0.0000027 & - & - \\
3 & E & -0.159 & 0.00069 & n.a. & -0.011 & n.a. \\
& s.e. & 0.208 & 0.00026 & - & 0.008 & - \\
4 & E & 0.126 & n.a. & n.a. & -0.022 & 0.000028 \\
& s.e. & 0.188 & - & - & 0.010 & 0.000011 \\
SOI & & & & & & \\
1 & E & -0.041 & 0.0078 & n.a. & n.a. & n.a. \\
& s.e. & 0.041 & 0.0046 & - & - & - \\
2 & E & 0.070 & -0.0021 & -0.0019 & n.a. & n.a. \\
& s.e. & 0.054 & 0.0053 & 0.0007 & - & - \\
3 & E & 0.059 & 0.0072 & n.a. & -0.004 & n.a. \\
& s.e. & 0.224 & 0.0050 & - & 0.010 & - \\
4 & E & -0.0041 & n.a. & n.a. & -0.0015 & 0.00032 \\
& s.e. & 0.229 & - & - & 0.0100 & 0.00021 \\
\hline
\end{tabular}

Table 6. Number of parameters $(K)$, residual sum of squares (RSS), AICc, $\triangle$ AICc, Akaike weights $\left(\omega_{\mathrm{i}}\right)$ and the coefficient of determination $\left(R^{2}\right)$ for models of barn owl population dynamics in southern Scotland and the winter North Atlantic Oscillation (NAO)

Data are from 1979 to 1990 . The best-fitting model is shown in bold

\begin{tabular}{lccrccc}
\hline Model & $K$ & RSS & \multicolumn{1}{c}{ AICc } & $\Delta$ AICc & $\omega_{\mathrm{i}}$ & $R^{2}$ \\
\hline $\mathbf{1}$ & $\mathbf{3}$ & $\mathbf{2 . 1 0 7 0}$ & $-\mathbf{- 1 1 . 8 7 5 9}$ & $\mathbf{0}$ & $\mathbf{0 . 4 9 4 8}$ & $\mathbf{0 . 0 0 1}$ \\
2 & 4 & 2.0858 & -7.2827 & 4.5932 & 0.0498 & 0.011 \\
3 & 4 & 1.6279 & -10.2568 & 1.6191 & 0.2202 & 0.228 \\
4 & 4 & 1.6101 & -10.3892 & 1.4867 & 0.2353 & 0.236 \\
\hline
\end{tabular}

Table 7. Parameter estimates (E) and standard errors (s.e.) for models of barn owl population dynamics in southern Scotland and the winter North Atlantic Oscillation (NAO)

Data are from 1979 to 1990 . The best-fitting model is shown in bold. n.a. $=$ not applicable

\begin{tabular}{lcrcccc}
\hline Model & \multicolumn{7}{c}{ Model parameter } \\
& \multicolumn{7}{c}{$a$} & $b$ & $c$ & $d$ & $f$ \\
\hline $\mathbf{1}$ & $\mathbf{E}$ & $\mathbf{- 0 . 0 0 6}$ & $\mathbf{- 0 . 0 0 6}$ & n.a. & n.a. & n.a. \\
& s.e. & $\mathbf{0 . 1 7 7}$ & $\mathbf{0 . 0 7 7}$ & - & - & - \\
2 & E & -0.022 & 0.054 & -0.014 & n.a. & n.a. \\
& s.e. & 0.193 & 0.214 & 0.047 & - & - \\
3 & E & 0.499 & -0.010 & n.a. & -0.016 & n.a. \\
& s.e. & 0.351 & 0.071 & - & 0.010 & - \\
4 & E & 0.482 & n.a. & n.a. & -0.015 & -0.001 \\
& s.e. & 0.328 & - & - & 0.011 & 0.003 \\
\hline
\end{tabular}

\section{Discussion}

Effects of climate on wildlife population dynamics are often reported (Andrewartha and Birch 1954; Caughley et al. 1987;
Newton 1998). In the present study, the grey heron, malleefowl and barn owl populations demonstrated contrasting magnitudes of effects of climate on annual dynamics. The herons and malleefowls showed strong relationships with climate and the owls showed no such relationships. The results in the present study were broadly similar to, but also different in detail from, those reported elsewhere. The results were obtained by formal analysis rather than visual assessment of apparent patterns.

Grey herons in Britain are reported to be very sensitive to severe winters (as indicated by negative values of the winter NAO) but fast to recover from population crashes (Stafford 1971). However, the assessment had not been based previously on analysis of the form reported here. Although there were general, weak patterns for grey herons, there were several instances where decreases in grey heron abundances as a consequence of severe winters were not observed between 1928 and 1969. These departures were not reported in several text books (e.g. Putman and Wratten 1984; Caughley and Sinclair 1994; Newton 1998; Begon et al. 2006). For example, from 1935 to 1936, grey heron growth rate was very slightly negative despite a severe (NAO $=-3.89)$ winter (Fig. 5). In the winter of 1968-69, grey heron annual $r$ remained positive despite a severe winter with the NAO of -4.89 , the lowest value observed during the study (Fig. 5). There may not always be a direct association between winter NAO and temperature. For example, the winter from 1962 to 1963 had a less negative value for the winter NAO $(\mathrm{NAO}=-3.60)$ than did the later 1968-69 winter $(\mathrm{NAO}=-4.89)$; however, the number of days when the temperature was below freezing was greater for 1962-63 (Besbeas et al. 2002). It has been suggested (Lack 1954) that the most likely density-dependent factors operating in the grey heron population are intraspecific competition and food shortages. Time-series models of population fluctuations for the grey heron over a 70-year period in southern Britain found a lack of significant density-dependent effects (Lande et al.2002). Although density-dependent factors were not considered to be absent, they were considered not to be strongly influential relative to climate, on average. It is possible that the effects of density dependence may have been 'masked' by several periods of density independent growth related to the winter NAO.

The malleefowl population's dynamics were related to rainfall, as reported previously (Priddel and Wheeler 2003), and to a lesser extent the SOI, although differently for each climate parameter. Rainfall and SOI were not correlated so different results can be expected. The positive effect of rainfall may be related to food availability or to the role of rain in heating eggs in the earth mound through the decomposition of wet leaf litter (Frith 1962; Priddel and Wheeler 2003). However the population had low annual growth rates, being mostly negative, even with high rainfall. The low annual $r$ values may be associated with high predation rates by predators such as foxes (Vulpes vulpes) (Priddel and Wheeler 1996), because no fox control other than occasional shooting occurred during the study (Priddel and Wheeler 2003). The estimated maximum annual growth rate of 0.07 is presumably an underestimate of the annual intrinsic growth rate $\left(r_{\mathrm{m}}\right)$. The linear relationship with rainfall was the best-fitting model. In contrast, Priddel and Wheeler (2003) reported a significant quadratic relationship with rainfall, although in that study, only the quadratic 
regression with rainfall was reported and the relative support for the linear model was not reported. The fitted quadratic equation with rainfall reported here is slightly different in parameter estimates and fit from that reported by Priddel and Wheeler (2003). The differences may simply be associated with rounding errors in analysis. The curved relationship between annual $r$ and SOI is a shape (parabolic) similar to a curved relationship for kangaroos and rainfall (Caughley et al. 1984).

In contrast to grey herons and malleefowl, barn owls showed no relationship with the climate (winter NAO). The best fit, as assessed by the AICc analysis, was the Model 1 (Table 6). The Akaike weight $\left(\omega_{1}\right)$ of the best model was 0.495 but the model had no support as assessed by $R^{2}(0.001)$ (Table 6$)$. These results support the suggestion (Taylor 1994) of a poor association between weather-related variables and barn owls. It is noted that the multiple linear regression of $r$ and food and density (eqn 3.3 of Hone and Sibly 2002) had an $R^{2}$ of 0.82 , so clearly had vastly more support than the best-fitting linear regression of $r$ and climate (winter NAO). These results demonstrate clearly the difference between relative support for a model, as assessed by Akaike weight, and support for a model assessed by $R^{2}$. The latter assesses support for one model at a time.

The study period for barn owls from 1979 to 1990 was much shorter than that for herons from 1928 to 1969 . The predominance of a positive phase of the NAO associated with warmer and wetter winters from 1979 to 1990 means the barn owl population may not have been limited by the colder conditions that affected the heron population. The heron is a waterbird and the freezing of wetlands during negative phases of the NAO may affect the accessibility of food, a factor not influential in the ability of the barn owl to obtain food. The results reported here, together with those of Taylor (1994) and Hone and Sibly (2002), demonstrate the advantages of mechanistic analysis for effects of food on annual population growth rate.

The results obtained in the present study suggest that any future climate change may have different effects on the population dynamics of each of the three bird species. Grey heron and malleefowl populations may be influenced directly by changes in climate, whereas barn owls may not be directly influenced.

\section{Acknowledgements}

We thank the University of Canberra for support.

\section{References}

Anderson, D. R. (2008). 'Model Based Inference in the Life Sciences. A Primer on Evidence.' (Springer: Berlin.)

Andrewartha, H., and Birch, L. C. (1954). 'The Distribution and Abundance of Animals.' (Chicago University Press: Chicago, IL.)

Begon, M., Townsend, C. R., and Harper, J. L. (2006). 'Ecology: From Individuals to Ecosystems.' 4th edn. (Blackwell Publishing: Oxford, UK.)

Berryman, A. A., Gutierrez, A. P., and Arditi, R. (1995). Credible, parsimonious and useful predator-prey models - a reply to Abrams, Gleeson and Sarnelle. Ecology 76, 1980-1985. doi:10.2307/1940728

Besbeas, P., Freeman, S. N., Morgan, B. J. T., and Catchpole, E. A. (2002). Integrating mark-recapture-recovery and census data to estimate animal abundance and demographic parameters. Biometrics 58, 540-547. doi:10.1111/j.0006-341X.2002.00540.x
Burnham, K. P., and Anderson, D. R. (2001). Kullback-Leibler information as basis for strong inference in ecological studies. Wildlife Research 28, 111-119. doi:10.1071/WR99107

Caughley, G., and Sinclair, A. R. E. (1994). 'Wildlife Ecology and Management.' (Blackwell Scientific Publications: Oxford, UK.)

Caughley, J., Bayliss, P., and Giles, J. (1984). Trends in kangaroo numbers in western New South Wales and their relation to rainfall. Australian Wildlife Research 11, 415-422. doi:10.1071/WR9840415

Caughley, G., Shepherd, N., and Short, J. (1987). 'Kangaroos. Their Ecology and Management in the Sheep Rangelands of Australia.' (Cambridge University Press: Cambridge, UK.)

Chamberlin, T. (1965). The method of multiple working hypotheses. Science 148, 754-759.

Coulson, T., Rohani, P., and Pascual, M. (2004). Skeletons, noise and population growth: the end of an old debate? Trends in Ecology \& Evolution 19, 359-364. doi:10.1016/j.tree.2004.05.008

Frith, H. J. (1962). 'The Mallee-fowl: the Bird that Builds an Incubator.' (Angus and Robertson: Sydney.)

Hone, J., and Clutton-Brock, T. H. (2007). Climate, food, density and wildlife population growth rate. Journal of Animal Ecology 76, 361-367. doi:10.1111/j.1365-2656.2006.01200.x

Hone, J., and Sibly, R. M. (2002). Demographic, mechanistic and densitydependent determinants of population growth rate: a case study in an avian predator. Philosophical Transactions of the Royal Society of London. Series B, Biological Sciences 357, 1171-1177. doi:10.1098/ rstb. 2002.1118

Hone, J., Krebs, C. J., and O'Donoghue, M. (2011). Is the relationship between predator and prey abundances related to climate for lynx and snowshoe hares? Wildlife Research 38, 419-425. doi:10.1071/WR11009

Hurrell, J. W. (1995). Decadal trends in the North Atlantic Oscillation: regional temperatures and precipitation. Science 269, 676-679. doi:10.1126/science.269.5224.676

Hurrell, J. W., Kushnir, Y., Visbeck, M., and Ottersen, G. (2003). An overview of the North Atlantic Oscillation: climate significance and environmental impact. Geophysical Monograph Series 134, 1-35. doi:10.1029/134GM01

Johnson, J. B., and Omland, K. S. (2004). Model selection in ecology and evolution. Trends in Ecology \& Evolution 19, 101-108. doi:10.1016/ j.tree.2003.10.013

Knape, J., and de Valpine, P. (2011). Effects of weather and climate on the dynamics of animal population time series. Proceedings of the Royal Society of London. Series B. Biological Sciences 278, 985-992. doi:10.1098/rspb.2010.1333

Lack, D. (1954). 'The Natural Regulation of Animal Numbers.' (Oxford University Press: New York.)

Lande, R., Engen, S., and Saether, B. E. (2002). Estimating density dependence in time-series of age-structured populations. Philosophical Transactions of the Royal Society of London. Series B, Biological Sciences 357, 1179-1184. doi:10.1098/rstb.2002.1120

May, R. M. (1974). 'Stability and Complexity in Model Ecosystems.' (Princeton University Press: Princeton, NJ.)

May, R. M. (1981). Models for two interacting populations. In 'Theoretical Ecology. Principles and Applications. 2nd edn. (Ed. R. M. May.) pp. 78-104. (Blackwell: Oxford, UK.)

Newton, I. (1998). 'Population Limitation in Birds.' (Academic Press: London.)

North, P. M., and Morgan, B. J. T. (1979). Modelling heron survival using weather data. Biometrics 35, 667-681. doi:10.2307/2530260

Priddel, D., and Wheeler, R. (1996). Effects of age at release on the susceptibility of captive-reared malleefowl Leipoa ocellata to predation by the introduced fox Vulpes vulpes. Eти 96, 32-41. doi:10.1071/MU9960032

Priddel, D., and Wheeler, R. (2003). Nesting activity and demography of an isolated population of malleefowl (Leipoa ocellata). Wildlife Research 30, 451-464. doi:10.1071/WR02046 
Putman, R. J., and Wratten, S. D. (1984). 'Principles of Ecology.' (Croom Helm: London.)

Sæther, B. E., Engen, S., Møller, A. P., Matthysen, E., Adriansen, F., Fiedler, W., Leivits, A., Lambrechts, M. M., Visser, M. E., Anker-Nilssen, T., Both, C., Dhondt, A. A., McCleery, R. H., McMeeking, J., Potti, J., Røstad, O. W., and Thomson, D. (2003). Climate variation and regional gradients in population dynamics of two hole-nesting passerines. Proceedings of the Royal Society of London. Series B. Biological Sciences 270, 2397-2404.

Sibly, R. M., and Hone, J. (2002). Population growth rate and its determinants. Philosophical Transactions of the Royal Society of London. Series B, Biological Sciences 357, 1153-1170. doi:10.1098/rstb.2002.1117
Stafford, J. (1971). The heron population of England and Wales 1928-1970. Bird Study 18, 218-221. doi:10.1080/00063657109476316

Stenseth, N. C., Ottersen, G., Hurrell, J. W., Mysterud, A., Lima, M., Chan, K. S., Yoccoz, N. G., and Ådlandsvik, B. (2003). Studying climate effects on ecology through the use of climate indices: the North Atlantic Oscillation, El Niño-Southern Oscillation and beyond. Proceedings of the Royal Society of London. Series B. Biological Sciences 270, 2087-2096. doi:10.1098/rspb.2003.2415

Taylor, I. (1994). 'Barn Owls. Predator-Prey Relationships and Conservation.' (Cambridge University Press: Cambridge, UK.) 